\title{
Da mercadorização do corpo feminino: um estudo sobre a imagem fotográfica da mulher nua
}

\author{
Nestor Persio Alvim Agricola \\ Mestre em Educação (Universidade Federal de Goiás) \\ Professor na Universidade Federal de Goiás \\ nestoralvim@hotmail.com
}

\begin{abstract}
Resumo Este trabalho consiste no relato de uma pesquisa realizada durante o ano de 2009, sob as bases da fenomenologia, em que o objeto de estudo foi o corpo nu feminino exibido como forma de arte nas publicações de nome Playboy editadas em 2008. O método utilizado foi a análise fotográfica, de Roland Barthes (2005), que trata a fotografia como fenômeno passível de leitura e que compõe o quadro do que ganhou denominação de indústria cultural. O artigo trata, sobretudo, do corpo feminino na sociedade contemporânea, sua constituição estética padronizada e os mecanismos de depreciação a que está submetido.
\end{abstract}

Palavras-chave: fotografia; corpo; mulher; mercadoria; indústria cultural

\section{Introdução}

dinâmica de constituição da mensagem midiática nem sem-

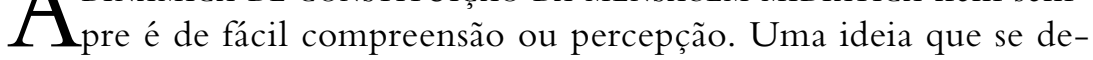
senvolveu e ganhou forças nas últimas décadas revela-se como objeto de análise desses mecanismos constitutivos de percepção da realidade, que é: corpo malhado é uma necessidade social. Essa ideia encontra forte referência, sobretudo nos mecanismos midiáticos de informação, nas programações televisivas que reforçam o que vem se tornando um parâmetro de sociabilidade. Silva e Gomes (2008, p. 197) afirmam que "o corpo jovem, malhado nas academias de ginástica, é ícone da sociedade contemporânea". Este texto trata, sobretudo, do corpo feminino na sociedade contemporânea e os mecanismos de depreciação a que está submetido procurando relacioná-lo com arte produzida sob a égide da reprodução técnica própria da sociedade industrial capitalista.

Para entendermos a ideia de valorização do corpo malhado e a dimensão que tal mensagem atinge no contexto da sociedade contemporânea, é necessário pensarmos sobre a constituição e a organização da dimensão sociocultural do homem. Todo grupo social estabelece regras, normas e padrões que se configuram como a base da organização social, a superestrutura imaterial sobre a qual se organizam todos os comportamentos socialmente estabelecidos, levando o sujeito ao compartilhamento de dadas necessidades e desejos que são então cultivados internamente ao grupo, caracterizando o consenso, a aceitação e adequação aos padrões de comportamentos.

Ao se estabelecerem padrões de comportamentos sociais para o grupo, podemos entender que passam a existir ações que funcionam como pré-requisitos para a constituição grupal. Esses com- 
portamentos estão situados na esfera dos desejos, entretanto referenciados nas normas sociais constituídas, que apresentam como marca a padronização, a semelhança. A padronização de comportamentos, por sua vez, se dá pelo desenvolvimento de estruturas de pensamento que se organizam com base em uma dada razão, uma dada lógica a partir da qual todos os seres humanos são educados. Silva e Gomes (2008, p. 198) a definem como "produção cultural [...] lógica que define o modo de viver das pessoas em sociedade, mesmo que elas não tenham consciência”.

Os costumes se estabelecem e se modificam, e todas as mudanças e alterações na constituição da sociedade implicam mudanças também na constituição psíquica do homem. Nem sempre o mecanismo que constitui um desejo é o mesmo para a constituição de uma regra. No entanto, a racionalidade e a lógica de constituição de um é reproduzida no outro. Razão instrumental, esta é a denominação corrente dada a um modelo de conformação do pensamento que caracteriza a sociedade industrial capitalista. Sua marca é a semelhança, a estandardização dos padrões de referência. Essa chamada racionalidade instrumental (Horkheimer, 2000) revela-se um implacável monopólio, que a tudo transmite um ar de semelhança, e implica sempre a busca do novo, do descartável, do efêmero, da produção e reprodução dos mecanismos de facilitação da vida. A mesma dinâmica que orienta a produção industrial em larga escala é reproduzida no pensamento e no comportamento da vida cotidiana dos indivíduos. Esse mecanismo social fortemente vinculado ao modo de produção capitalista ainda encontra outro fenômeno que o potencializa em dimensões estratosféricas, a mídia.

Os instrumentos midiáticos, que nasceram como mecanismos de facilitação da vida, transformam-se então no mais poderoso criador e estabilizador do comportamento social (Pires, 2002). A razão instrumental, o consumismo, a implantação de desejos, a conformação do pensamento, enfim, os comportamentos socialmente constituídos encontram como veículo de sua disseminação na atualidade a mídia televisiva. Betti (1998) vem designar este veículo de comunicação de "Janela de Vidro", basicamente pelo fato de que sua proposta é reproduzir a vida existente, mesmo que a este fenômeno seja imputada a implantação de padrões de referência social. Daí, a sua linguagem ser elaborada no sentido de manipular desejos e ofertar uma visão de mundo.

É importante que se entenda que os mecanismos de mídia sustentam-se do real, ou seja, a mídia se alimenta do real para propor o ideal num movimento denominado de circularidade. A circularidade é o movimento que caracteriza o processo mediante o qual a mídia, ao mesmo tempo em que reproduz a vida existente, a alimenta com as informações que produz. Assim, os padrões estéticos que se constituem não se fazem de forma espontânea, mas estruturados na vida existente, nas realidades sociais que se encontram presentes no tempo e no espaço.

No conjunto desse arsenal informacional propagado pela "Janela de Vidro", o corpo e suas formas especificadas ganham espaço privilegiado como referência de beleza, ideal coletivo de saúde, estética imanente e natural da condição humana. Ali, o corpo adquire um formato, uma dimensão que se apresenta como única e eternamente jovem, luminoso, despido, musculoso. O padrão é estabelecido como comportamento social, reforçado pela mídia e deixa-nos a sensação de que é a única possibilidade, e mais, é implantando como desejo coletivo, constituindo, em grande medida, a identidade social.

O desenvolvimento da ideia de 'idolatria' ao corpo, à aparência, veio acompanhada da necessidade de exposição da forma física. Não se malha, trabalha um corpo, moldando-o, para deixá-lo encoberto, vestido. $\mathrm{O}$ apelo de sua exibição se faz tão presente quanto o ato de malhar. A necessidade de exposição do 'objeto de sacrifício' (corpo construído, moldado) se estabelece na mesma lógica da adaptação ao padrão social e cultural propagado pela TV. Segundo Goldberg e Ramos (2002), nem sempre o nu é visto como indecente, bem como nem sempre o vestido é visto como decente. Desse ponto de vista, o que conta são as medidas, as formas físicas é que irão determinar a decência e, portanto, a autoridade para sua exposição. A conformação do padrão estético corporal é percebida como geradora de uma moral, a 'moral da boa forma'. Nessa referência para o pensamento, o corpo sem marcas indesejáveis e sem excessos, mesmo nu, pode ser considerado decente, e se torna, nessa perspectiva, um valor.

O body building, que se encontra composto por um conjunto de procedimentos como cirurgias plásticas, uso de cosméticos, de massagens, preenchimentos e especialmente a malhação, é, para Goldberg e Ramos (2002), a resposta dos indivíduos às forças sociais, entre elas a mídia, que transforma a gordura em doença, em desleixo, em indecência.

Nesse sentido, o corpo, de sujeito passa a objeto, e a diferenciação entre o corpo natural e o corpo escultural se estabelece na mesma dinâmica da produção industrial, pela mesma lógica do mercado. Tanto que este corpo se torna publicidade, vendendo produtos, objetos e, especialmente, ele próprio. Essa exposição se estende socialmente, e qualquer um que cultive o corpo tem o direito de exibi-lo, como na cultura do 'Carioca',

Se há uma tendência de exposição do corpo que se tem, forjado, belo, esculpido, forte, simbólico, o corpo malhado, há de se buscar também formas diver- 
sas para a exibição deste corpo, e a mídia entra como ferramenta eficaz nessa missão. A televisão, a internet e a mídia impressa são os principais meios pelos quais se busca exibir os resultados de horas em academias e clínicas, ou do cumprimento de dietas rigorosíssimas na busca do corpo malhado, icônicos da mentalidade contemporânea. O que se revela realmente importante é estar em evidência, qualquer que seja o sacrifício exigido para tal.

Nessa visão, a forma física tende a valorizar especificamente a juventude, o corpo jovem, novo, sem marcas do tempo. O ideal social se transfere do homem adulto, responsável, trabalhador, para o jovem, descompromissado, rebelde e, o principal, corporalmente belo. Fica estabelecida assim a figura do jovem como ícone da cultura contemporânea, detentor do corpo escultural. É incomum a representatividade do corpo malhado em pessoas que estão acima da faixa etária considerada como juvenil (nesse caso, até trinta anos), conforme analisam Silva e Gomes (2008, p. 202) em um estudo feito sobre a série de televisão Malhação, da Rede Globo: "partes do corpo foram representadas em close, produzindo um efeito deliberado de aproximação sobre o telespectador, muitas vezes, obrigando-o não só a ver a superfície da imagem, mas a ser dominado e até esmagado por ela".

A tentativa de fazer da ficção a realidade é a marca desses atuais mecanismos de sugestões, prevalecendo a imagem do corpo malhado como ideal. Essa transferência acaba por produzir uma mudança gradual de comportamento e de valores que se estabelecem na relação do homem com o mundo. O corpo assume a função de expressividade e representatividade social porque se apresenta como ideal de estética na autoidentificação do sujeito no mundo.

A aparência física passa a determinar a figura humana, e a moral é uma moral do corpo, que subverte a antiga moral cristã e relativiza a exibição do corpo nu, desde que belo. Vivemos assim uma disfarçada ditadura da aparência.

O que nos parece é que a criação e o cultivo do 'hipercorpo' se dão pela tentativa de subverter a sociedade com uma ideia fictícia de que a forma malhada do corpo se sobrepõe à fraqueza, à falha, ao medo, à saúde e até à idade, ou seja, o ser pode até envelhecer, mas o corpo malhado traz a ideia de vigor e vitalidade, como se fosse possível driblar o inexorável envelhecimento do corpo. Percebe-se a prevalência dos ideais mercadológicos da produção industrial em larga escala, da racionalidade instrumental que tende a disfarçar a realidade e a substituir o alvo da atenção coletiva para o que apresenta um forte apelo na aparência.

Enfim, temos um padrão social, muitas vezes imposto, de que se deve construir um corpo para atender aos conceitos sociais recentemente estabelecidos a fim de se esconder uma realidade que pode não condizer com o padrão.

\section{Imagem corporal, signo social}

A evolução tecnológica observada no século XX trouxe transformações profundas na sociedade, muitas delas desencadeadas pela cultura de massa e os seus meios de comunicação. Jornais, revistas, cinema, tevê, cada qual proporcionando envio de informações e, em consequência, consolidando conceitos, ditando valores, moldando a maneira de pensar e de agir de milhões de pessoas, num movimento circular de exposição, afirmação e interpretação do mundo real. Nesse contexto, encontr-se o corpo visto, percebido e representado na mídia com sua diversidade de possibilidades de construções de interpretações referenciadas no contexto da sociedade do consumo.

Nosso objeto de estudo, entretanto, é o corpo em si, o corpo apresentado e representado na mídia, o corpo, suas formas e a mensagem social que o acompanha. Nesse sentido, optamos por um instrumento metodológico bastante específico, bem como por uma estratégia de análise pouco conhecida ou difundida, mas extremamente fértil. Trata-se do método de análise fotográfica ensaiado por Barthes (2005) na obra Teoria da cultura de massa, organizada por Lima (2005). Nesta obra, Barthes publica o texto A Mensagem Fotográfica, no qual nos fornece ferramentas consistentes para a análise sociológica da fotografia como mensagem e dá fortes indicações de como se constitui a chamada mensagem fotográfica, composição de significantes que acompanham a imagem como reprodução da realidade.

Segundo Barthes (2005), a fotografia como reprodução de imagens se constitui como componente da cultura de massa, veículo destinado à massa da população que se pretende portador de significados que também são estabelecidos socialmente como mensagens que adquirem sentido num contexto específico. Ao se considerar dois elementos componentes da fotografia, emissor e receptor da mensagem fotográfica, fica clara a potencialidade deste instrumento midiático como formador de comportamentos. Como a proposta deste estudo é a análise da imagem corporal contemporânea, elegemos a fotografia como seu veículo privilegiado. Nosso objeto, portanto, é a imagem corporal exposta na revista Playboy, que se mostra como reprodutora de um ideal de corpo feminino. Como amostra, foram selecionadas as edições da Playboy do ano 2008. Nessas publicações, fizemos um recorte da análise fotográfica que envolveu somente a modelo de capa de nove edições da revista. A escolha desse veículo se deu pelo fato de ser uma publicação que tem como tema principal o corpo, a imagem corporal, a forma, a estética e, além disso, por ser um veículo de grande consumo. Obviamente, nosso objeto fica restrito ao corpo feminino, pela própria natureza da publicação selecionada. 
Segundo Barthes, a mensagem fotográfica apresenta dois componentes, a mensagem denotada e a mensagem conotada. À primeira vista, a imagem fotográfica não apresenta código, seu conteúdo é o que está exposto e nada mais. Entretanto, num exame mais detalhado, nota-se que o objeto fotografado se apresenta sempre em dado contexto, afirmativo, revitalizado, contestador, polêmico, que subscreve o conteúdo da mensagem e nos fornece elementos para sua leitura e interpretação.

De fato, cada uma dessas mensagens desenvolve de maneira imediata e evidente, além do próprio conteúdo analógico (cena, objeto, paisagem), uma mensagem suplementar, que é o que se chama comumente o estilo da reprodução; trata-se pois de um segundo sentido, de que o significante é um certo tratamento da imagem sob a ação do criador, e cujo significado, quer estético, quer ideológico, remete a uma certa cultura da sociedade que recebe a mensagem (Barthes, 2005, p. 327).

Para os elementos que compõem a mensagem fotográfica, é particularmente importante que sejam definidos detalhes que formam cada quadro da realidade. Uma fotografia se pretende a reprodução fiel da realidade, eternizada em película como momento ímpar que não retorna. Contudo, o contexto em que se dá o quadro permite inferências que constituem a leitura fotográfica, a busca de significados para o que se pretende eternizar.

Partimos então da imagem denotada, pura e simples do que o quadro fotográfico nos mostra, e, a partir do levantamento detalhado e rigoroso do contexto, da cena, do objeto, da paisagem, criamos possibilidades de uma leitura em parte subjetiva da mensagem conotada, que pode ou não ser compartilhada por aqueles que observam a mesma imagem. A fotografia veiculada nos mecanismos de mídia impressa não é somente observada, mas essencialmente lida. Invariavelmente, ela apresenta elementos que possibilitam sua leitura, sua interpretação, sua mensagem conotada.

De fato há uma forte probabilidade para que a mensagem fotográfica seja também ela conotada. A conotação não se deixa forçosamente apreender imediatamente ao nível da própria mensagem, mas pode-se já induzi-la de certos fenômenos que se passam ao nível da produção e da recepção da mensagem. (Barthes, 2005, p. 328)

Na visão de Barthes, a mensagem denotada é desprovida de significantes, configurando-se exclusivamente como reprodução de um momento real. Já a mensagem conotada comporta um plano de expressão e um plano de conteúdo que permite a interpretação, a leitura da imagem tal qual um texto. "O objeto talvez não possua uma força, mas, por certo possui um sentido" (Barthes, 2005, p. 331).
O que objetivamente utilizamos como instrumento para análise do significado da fotografia foi, além da própria modelo e sua pose, tudo aquilo que acompanha a modelo na montagem do cenário específico para cada foto. Para isso, foram definidos alguns agrupamentos de objetos ou de detalhes que compõem o cenário da foto, tais como: o local da foto, as roupas da modelo, os objetos que integram o cenário, os acessórios que a modelo utiliza e, por último, o arranjo dos cabelos da modelo. Acreditamos que esses agrupamentos são suficientes para procedermos a uma leitura da mensagem fotográfica implícita em cada ensaio, e assim situarmos o corpo feminino e suas formas estéticas no contexto da indústria cultural. Para Barthes,

Esses objetos constituem excelentes elementos de significação: de um lado são descontínuos e completos em si mesmos, o que é para um signo uma qualidade física; e, de outro, remetem a significados claros, conhecidos; são portanto os elementos de um verdadeiro léxico, estáveis a ponto de se poder facilmente erigi-los em sintaxe. Eis, por exemplo uma composição de objetos: uma janela aberta sobre telhados de telha, uma paisagem de vinhedos; diante da janela, um álbum de fotografias, uma lupa, um vaso de flores. (Barthes, 2005, p. 331)

O conjunto desses detalhes que compõem o cenário, juntamente com o corpo fotografado, permite a leitura da imagem com grandes possibilidades de interpretação da mensagem que se deseja passar, seja implícita ou absolutamente explícita.

O desafio metodológico que enfrentamos diz respeito à validação da impressão pessoal, da leitura individual do pesquisador, como forma de conhecimento científico. Para solucionarmos esse impasse, valemo-nos da argumentação de Betti (1998), que, apoiado em Paul Ricoeur, faz a defesa da perspectiva fenomenológica hermenêutica para estudos dessa natureza. Para Betti, a interpretação de imagens é uma possibilidade tão real quanto qualquer outro dado empírico e quantitativo, revelando-se potencialmente muito mais rico, em termos de análise sistemática. "muitos tipos de ações e instituições culturais podem compartilhar as características do discurso contidas na imagem, e, consequentemente, serem lidos ou interpretados como se interpreta um texto" (Betti, 1998, p. 59).

Optamos, então, por uma organização metodológica em que procuramos definir categorias objetivas comuns que se fazem presentes em todos os ensaios e, a partir daí, buscamos a leitura das fotografias nos valendo de impressões subjetivas percebidas no conjunto do ensaio, nos elementos que compõem o cenário, nas expressões faciais e corporais da modelo. Apresentamos um quadro com os elementos objetivos que compõem o ensaio e, posteriormente, a leitura de cada ensaio. 
Quadro 1 - elementos objetivos que compõem cada ensaio

\begin{tabular}{|c|c|c|c|c|c|}
\hline $\begin{array}{l}\text { Categorias } \\
\text { modelos }\end{array}$ & Local do ensaio & Acessórios da modelo & Roupas & Objetos de cenário & Cabelo da modelo \\
\hline Modelo 1 & Quarto & $\begin{array}{l}\text { Colar com pingente, } \\
\text { brincos }\end{array}$ & $\begin{array}{l}\text { Camisola transpa- } \\
\text { rente, camisa }\end{array}$ & $\begin{array}{l}\text { Cortinado, cadeira, } \\
\text { cama }\end{array}$ & $\begin{array}{l}\text { Solto, liso e jogado } \\
\text { em diferentes posi- } \\
\text { ções }\end{array}$ \\
\hline Modelo 2 & Sala de estar & $\begin{array}{l}\text { Colar, pulseira, brin- } \\
\text { cos, asas feitas com } \\
\text { penas, sapato de sal- } \\
\text { tos altos }\end{array}$ & $\begin{array}{l}\text { Blusa, calcinha, bo- } \\
\text { tas de cano alto, } \\
\text { sutiã transparente, } \\
\text { espartilho }\end{array}$ & $\begin{array}{l}\text { Cortina, sofá verme- } \\
\text { lho, cama }\end{array}$ & $\begin{array}{l}\text { Solto, liso e jogado } \\
\text { em diferentes posi- } \\
\text { ções }\end{array}$ \\
\hline Modelo 3 & Praias do Nordeste & Não possui & $\begin{array}{l}\text { Blusa transparente, } \\
\text { calcinha, vestido } \\
\text { colorido }\end{array}$ & $\begin{array}{l}\text { Barco de pesca, rede } \\
\text { de balanço, cama }\end{array}$ & $\begin{array}{l}\text { Solto, liso e jogado } \\
\text { em diferentes posi- } \\
\text { ções }\end{array}$ \\
\hline Modelo 4 & Galpão & $\begin{array}{l}\text { Brincos, pulseira, co- } \\
\text { lar, piercing. }\end{array}$ & $\begin{array}{l}\text { Blusa frente única, } \\
\text { calça jeans com } \\
\text { lycra, calcinha fio } \\
\text { dental }\end{array}$ & $\begin{array}{l}\text { Holofotes, cama, esca- } \\
\text { da, mesa, cadeira }\end{array}$ & $\begin{array}{l}\text { Solto, liso e jogado } \\
\text { em diferentes posi- } \\
\text { ções }\end{array}$ \\
\hline Modelo 5 & $\begin{array}{l}\text { Hotel Pousada em Sal- } \\
\text { vador (Bahia) }\end{array}$ & $\begin{array}{l}\text { Colar, flor, rosário, } \\
\text { sombrinha, crucifixo }\end{array}$ & $\begin{array}{l}\text { Camisola branca, } \\
\text { saia rodada, cami- } \\
\text { sa, cinta liga, meia } \\
\text { calça, calcinha fio } \\
\text { dental }\end{array}$ & $\begin{array}{l}\text { Um coqueiro, um qua- } \\
\text { dro ao fundo com de- } \\
\text { senho de uma sereia, } \\
\text { cestos feitos manual- } \\
\text { mente }\end{array}$ & $\begin{array}{l}\text { Solto, liso e jogado } \\
\text { em diferentes posi- } \\
\text { ções }\end{array}$ \\
\hline Modelo 6 & Quarto & $\begin{array}{l}\text { Piercing, brincos, co- } \\
\text { lar, cinto }\end{array}$ & $\begin{array}{l}\text { Top transparente, } \\
\text { luvas, short, fitas } \\
\text { decoradas com pe- } \\
\text { nas, camisa }\end{array}$ & $\begin{array}{l}\text { Troféus, penteadeira } \\
\text { com espelho, sofá ver- } \\
\text { melho, colchão }\end{array}$ & $\begin{array}{l}\text { Solto, liso e jogado } \\
\text { em diferentes posi- } \\
\text { ções }\end{array}$ \\
\hline Modelo 7 & Galpão Abandonado & $\begin{array}{l}\text { Brincos, colar, coleira, } \\
\text { algemas, chicote }\end{array}$ & $\begin{array}{l}\text { Calcinha, mini blu- } \\
\text { sa de tela, meia } \\
\text { calça }\end{array}$ & $\begin{array}{l}\text { Cama velha, colchão } \\
\text { rasgado, cela de mon- } \\
\text { tar a cavalo, cadeira } \\
\text { de barbeiro, }\end{array}$ & $\begin{array}{l}\text { Solto, liso e jogado } \\
\text { em diferentes posi- } \\
\text { ções }\end{array}$ \\
\hline Modelo 8 & Apartamento & $\begin{array}{l}\text { Colar, brinco, pulseira, } \\
\text { anel }\end{array}$ & $\begin{array}{l}\text { Camisa de botão, } \\
\text { meia calça, calci- } \\
\text { nha, chapéu, colete }\end{array}$ & $\begin{array}{l}\text { Sofá com detalhes } \\
\text { dourados, piano de } \\
\text { cauda, livros, estante }\end{array}$ & $\begin{array}{l}\text { Solto, liso e jogado } \\
\text { em diferentes posi- } \\
\text { ções }\end{array}$ \\
\hline Modelo 9 & $\begin{array}{l}\text { Ruas e bares do subúr- } \\
\text { bio do Rio de Janeiro }\end{array}$ & $\begin{array}{l}\text { Colar, anel, pulseira, } \\
\text { brincos, óculos escu- } \\
\text { ros }\end{array}$ & $\begin{array}{l}\text { Meia calça, cole- } \\
\text { te, calcinha, capa } \\
\text { transparente }\end{array}$ & $\begin{array}{l}\text { Sofá, lâmpadas flo- } \\
\text { rescentes, mesa de } \\
\text { sinuca }\end{array}$ & $\begin{array}{l}\text { Solto, liso e jogado } \\
\text { em diferentes posi- } \\
\text { ções }\end{array}$ \\
\hline
\end{tabular}

Fonte: elaborado pelo autor, com base nas edições pesquisadas da revista Playboy do ano 2008.

\section{Modelo n. 1}

Leitura: as fotos procuram evidenciar uma ideia de pureza e inocência da modelo. Essa opinião é reforçada pela presença da cor branca que predomina no ensaio como fundo ou na tonalidade das roupas. A modelo exibe uma expressão de acanhamento como se estivesse sendo violada em sua intimidade, mas ao mesmo tempo nos deixa perceber uma atitude de mulher sensual pelo sorriso que exibe em certas fotos. 
Esse conjunto de fotos permite uma leitura segundo a qual o corpo da mulher deve ser preservado em sua inocência. Mas, ao mesmo tempo, uma inocência infantil que desperta para a sensualidade da vida adulta, revelando um ar de satisfação em ser observada. O corpo é magro, sem musculatura visível, branco pouco bronzeado, pouco revelador e reflete um proposital brilho que acentua o sentido de pureza. Os elementos que compõem a foto são discretos e pequenos, como de mulher recém saída da infância e adolescência.

\section{Modelo n. 2}

Leitura: a modelo, ao mesmo tempo em que veste asas conotando a imagem de um anjo, aparece com uma imagem bastante erótica, com cores fortes e marcantes. Na pose corporal, alterna-se um visual angelical e um visual subversivo, despudorado. As fotos revelam uma atitude de mulher forte, independente, que se mostra como alguém que se liberta das convenções sociais sem remorsos e culpas. Expõe o corpo de uma mulher forte, malhada, com músculos visíveis, bronzeada, que se vale de uma atitude independente, ao mesmo tempo em que revela uma evidente sexualidade. A imagem é de uma mulher que é capaz de uma pureza angelical e de um erotismo ilimitado, capaz de todo tipo de estratégia para a sedução. O corpo é irrestrito, corpo que não admite a repressão imposta pelo conservadorismo do mundo, que, ao mesmo tempo em que é puro, é erótico.

\section{Modelo n. 3}

Leitura: a modelo é uma ex-participante de reality show oriunda do Nordeste do país que mostrou nas telas de televisão uma forma de linguagem e de comportamento específicos. Nesse ensaio, a tentativa é a de expor a modelo como fruto do Nordeste, da cultura nordestina. Assim, as paisagens que a acompanham são representativas das belezas naturais da Região e a analogia que se faz é de que a modelo é uma das belezas naturais do Nordeste. A praia se faz presente como cenário constante. A modelo é enquadrada como parte de um cenário sempre impecável que a apresenta como componente natural desse cenário. Temos a forte impressão de calor revelada pela presença constante do sol e pelas roupas transparentes e leves, deixando-nos pressupor que as formas corporais são um produto forjado pela natureza nordestina, pelos ventos, mares, areias e vegetação. Interessante perceber como essa associação das belezas nordestinas com a nudez feminina é naturalizada, como se fosse uma prática comum visitar as praias do Nordeste e se deparar com belas mulheres nuas.

\section{Modelo n. 4}

Leitura: a modelo é dançarina de um grupo de Funk carioca caracterizado pelas danças sensuais e eróticas. Essa modelo também se destaca pelas formas corporais bastante avantajadas, situando-a até mesmo como fora do próprio padrão estético exibido pela revista, em geral. Devido ao exagero das formas corporais, a modelo recebeu um codinome que a compara com uma fruta tropical brasileira, que também é caracterizada pelo tamanho avantajado. Esse ensaio se dá em local fechado, com luminosidade artificial, talvez com a intenção de disfarçar imperfeições do corpo. A modelo está sempre distante da câmera e os braços estão sempre jogados para cima ou para traz, o que diminui as medidas abdominais. Nota-se que as fotos foram muito bem trabalhadas, as poses bem escolhidas, marcando o ensaio pela pouca espontaneidade. Apesar do grau de sensualidade da dança Funk carioca, as fotos da modelo foram pouco reveladoras, tudo isso em função de disfarçar formas físicas que estão evidentemente além do padrão. Embora a modelo esteja com medidas corporais muito acima do padrão da revista, a sua presença vem de uma audiência popular alcançada em programas de TV, nos quais a modelo exibe formas avantajadas, mas sobretudo passos de dança extremamente sensuais. Por isso, os cuidados com a foto, no sentido de não revelar isso que é considerado uma deformação estética.

\section{Modelo n. 5}

Leitura: semelhante ao ensaio da modelo n. 3, o cenário é o Nordeste, especificamente a Bahia. São também ressaltadas as belezas naturais do local, mas, diferentemente do ensaio n. 3, aqui o cenário é extremamente requintado. O hotel de locação do ensaio é classificado como de alto luxo, conotando o sentido de mulher também 'de luxo'. As paisagens naturais são da própria pousada e são alternadas com cenários internos sempre muito luxuosos. A modelo alterna fotos recatadas com fotos ousadas. A cor que predomina tanto em roupas, acessório e cenário é o vermelho, denotando calor. A sensação que permanece é que a mulher é um artigo de luxo, caro, para poucos, e principalmente objeto, adquirível, que pode se revelar verdadeiro objeto sexual. As formas corporais são semelhantes aos outros ensaios, com três características básicas: magra, malhada e branca, embora os contornos musculares não sejam muito evidentes. 


\section{Modelo n. 6}

Leitura: essa modelo tem uma relação direta com a Educação Física, provavelmente como estudante do curso ou como professora, revelando uma familiaridade com objetos que fazem parte da vida cotidiana do profissional. Representa um ideal de saúde que se materializa na estética do corpo, deixando pressupor a relação expressa na frase "atividade física é saúde". Outra aproximação que se faz é implicitamente da modelo à modalidade esportiva reconhecida como paixão nacional, o futebol. Da mesma forma que o futebol exerce um especial fascínio na população brasileira, essa modelo exerceria o mesmo efeito em função de sua beleza. O que é marcante, no entanto, é a analogia que se faz no ensaio de que a paixão pelo futebol se materializa em dois locais específicos, a sala de televisão e o campo de futebol. Assim, as fotos são na sala de televisão e no campo de futebol, reforçando a relação entre a mulher bonita, como produto e paixão nacional, e o futebol. A modelo, em certo momento, é colocada junto aos troféus, conotando a ideia segundo a qual ela mesma é o maior troféu. O corpo é posto então como recompensa não de um hábito saudável, mas de uma paixão pelo esporte. Também neste ensaio as características básicas da modelo são: magra, malhada e branca, sem definições musculares muito acentuadas.

\section{Modelo n. 7}

Leitura: tal qual o ensaio de n. 3, a modelo também é ex-participante de reality show da TV que se identificou, ao longo de sua participação, com uma postura popular, de uma classe social desprivilegiada, assumindo todo um comportamento 'irreverente' durante o programa. Isso inspirou um tema ao ensaio que foi de uma mulher do povo, pobre e que habita condições precárias de vida, uma mulher bonita, mas de condição econômica de classe baixa. No ensaio, ela aparece em meio a objetos usados, de aparência precária, e, em meio a esse quadro, vemos um corpo feminino que aparenta certa vulgaridade. Uma mulher que se submete à analogia com animais, aparecendo ao lado de uma cela de cavalo, os elementos que compõem os cenários são objetos cotidianos próprios de classe social baixa. A imagem que fica é de uma mulher vulgar, talvez de uma garota de programa, muito bela, mas que, oriunda da classe pobre, se rende às dificuldades e imposições financeiras. As formas corporais evidenciam contornos musculares mais proeminentes, destacados por uma proposital umidade da pele que nos dá a ideia de suor, de esforço, de sacrifício.

\section{Modelo n. 8}

Leitura: a modelo tem traços faciais bastante marcantes e aparece acompanhada de um cenário e de objetos requintados, deixando a conotação de ser uma mulher de elite. Todo o aparato de produção das fotos foram muito bem trabalhados no intuito de afastar qualquer sentido de vulgaridade da modelo e sua imagem está fortemente associada a objetos raros, caros e de acesso restrito. O piano de cauda, os livros, o sofá, tudo traz uma conotação de representação de classe rica, detentores de capital. Apesar disso, o corpo não deixa de ser análogo aos objetos, conotando também a modelo como objeto, mas objeto de elite. O corpo é branco, magro e apresenta uma sensualidade recatada, no entanto uma expressão de felicidade. Os contornos musculares são suaves. Não deixamos de associar a imagem à oferta do corpo feminino, um corpo caro, para poucos.

\section{Modelo n. 9}

Leitura: neste ensaio, a modelo denota ser uma prostituta que habita e trabalha nas ruas e prostíbulos da periferia do Rio de Janeiro. O bar, a mesa de sinuca, os homens que a acompanham, todos são emblemáticos para essa leitura de uma mulher que trabalha com o prazer alheio. Uma raridade nos ensaios desta revista aparece aqui, a presença de outras pessoas nas fotos, conotando o sentido segundo a qual a mulher é sem-dono, de propriedade de todos. Ela revela ainda um apelo sexual muito forte pelas roupas e acessórios usados e, em dada foto, aparece em frente a um quadro negro, como se estivesse dando uma aula cujo tema é o sexo. Não deixamos de associar a imagem da mulher à comercialização de seu corpo, como objeto de prazer, mas como alguém que se compraz dessa situação de mulher objeto sexual. O corpo é sensivelmente mais musculoso, trabalhado, embora magro e branco.

\section{Corpo feminino mercadoria}

A padronização a que o corpo feminino se encontra sujeito nesses tempos de mundialização da mídia encontra-se associada a uma lógica nascida e reforçada no modo de produção industrial, na racionalidade instrumental voltada para a acumulação do lucro em uma magnitude sem precedentes. O corpo feminino retratado aparece envolto numa mensagem conotada que o define invariavelmente como objeto, como algo que se encontra implicitamente à venda, desprovido de personalidade. $\mathrm{O}$ corpo exposto não denota 
a pessoa por trás da imagem, mas uma personalidade forjada, conferida pela própria produção da imagem. Essa personalidade forjada povoa o imaginário social acerca da mulher de corpo bonito, da mulher da mídia, que a concebe como produto, como coisa, como invariante da lógica moderna.

A moda é estabelecida em elementos da imagem que estão estandardizados, como os cabelos das modelos, os cortes de roupas íntimas, os sapatos de salto altíssimos e até mesmo as medidas corporais expostas, que raramente são diferentes dos $80 \mathrm{~cm}$ de busto, $60 \mathrm{~cm}$ de cintura e $90 \mathrm{~cm}$ de quadril. Esses detalhes aparecem sempre iguais nos ensaios observados. O corpo apresenta-se sempre igual, com poucas variações de sua estrutura estética. Com exceção de uma única modelo que se apresenta como além do padrão estabelecido, os corpos são sempre magros, brancos, pouco bronzeados e mais ou menos malhados. Há uma sensível variação na definição muscular de umas para outras modelos, mas que não chegam a marcar uma variação no padrão estético. Essas pequenas diferenças percebidas não chegam a estabelecer diferentes modelos estéticos, mas os expõem como particularidades individuais. Uma das questões que ficam é: se as formas são tão semelhantes, porque mostrar praticamente o mesmo corpo de edição a edição? Este questionamento só pode ser respondido coerentemente se concordarmos que a imagem conotada é o que se torna mais importante como mensagem midiática. É uma suposta personalidade que irá povoar o imaginário e alimentar a libido masculina. Os objetos e cenários que compõem os ensaios dão conotações de classe social evidentes, permitindo que não só o desejo circule pelo universo social, mas que a própria modelo esteja estabelecida como produto de classe, como objeto construído e moldado na classe social a que se destina. "Os mecanismos da indústria cultural procuram dar a seus consumidores aquilo que 'eles querem', que já esperam" (Vaz, 2006, p. 17).

Há um processo mútuo de definição do padrão exposto, isto é, ao passo que o veículo midiático se vale do mundo real como conteúdo estético, o mundo real define suas tendências e seus padrões estéticos utilizando como modelo a mídia. Uma das marcas desse processo circular é que o consumidor da revista não precisa imaginar, fantasiar as possíveis características da persona que se apresenta nua; a revista faz isso, conotando para cada ensaio um ambiente que se subentende próprio da mulher que se mostra. Em outras palavras, a revista exime o leitor de elaborar, de forma imaginária, as particularidades da mulher, sua classe social, onde frequenta, de onde vem, o que veste etc. Conforme praticamente todos os mecanismos midiáticos dominados pela indústria cultural, também a fotografia da mulher nua já vem com suas possibilidades de leitura prontas, padronizadas.

A marca do processo ideológico é a substituição do esforço de pensar pela mera contemplação passi- va. No meio desse conflito, entre o homem como ser pensante e naturalmente ativo da práxis e a mecanização e maquinização das estruturas do pensamento, do desejo e da lógica pela indústria cultural, encontra-se o corpo nu feminino, violado, vulgarizado e desvalorizado como legado material da existência, configurando-se como produto, mercadoria, objeto. O corpo, que numa perspectiva otimista e ingênua é portador de sentidos e significados culturais, expressando hábitos, práticas, saberes e usos, sob a égide da indústria cultural revela-se como mercadoria comprável, desejável, aviltando a figura da mulher, que, a tão duras penas, vem conquistando sua posição de igualdade com relação ao homem ao longo dos tempos, e o eclipse da razão - se é que podemos parafrasear o título da obra de tão importante autor, Max Horkheimer - se encontra em considerarmos essa violação como algo da própria condição de liberdade do sujeito.

Comprar a revista e observar o corpo nu da mulher já não tem mais o caráter imoral que tinha em tempos antigos. $\mathrm{O}$ nu feminino é exposto como uma forma de arte que se apresenta viável a partir da condição de liberdade do sujeito. Tanto quem compra quanto quem vende (a imagem corporal nua) o fazem apoiados na ideia de liberdade de escolha e expressão e de legitimidade da arte da fotografia do nu. Sobre a arte, Benjamin (2005) nos dá indicações daquilo que, em seu conceito, necessita compor a obra de arte. Entre essas características, as principais são a originalidade e a expressividade, deixando claro o absurdo da ideia de comercialização que acompanhava a arte na primeira metade do século XX. Nesse sentido, a exposição do corpo da mulher, justificada como arte pelas publicações dessa natureza, estaria longe de atender às características puras da obra de arte, configurando-se como reprodução mercadorizada da imagem moldada.

A reprodução técnica da imagem fotográfica acompanha a lógica de mercado que a tudo quanto requer o status de arte é reproduzido em larga escala. Nesse contexto, o corpo feminino se conforma em objeto reproduzido, destituindo-o de humanidade, conferindo-lhe uma personalidade forjada, suposta e afirmativa do conjunto que compõe a fotografia. A estética do nu feminino exposta na revista Playboy parece estabelecer elementos que definem a sociabilidade contemporânea, na medida em que se diferencia e se assemelha à massa como possibilidade, mas que determina a visibilidade do corpo seja ele qual for. Uma vez estabelecida a visibilidade do corpo como parâmetro de sociabilidade, há que se buscar formas de adaptação desse corpo ao que se tornou esteticamente aceitável ou decente (Goldberg; Ramos, 2002). A valorização das formas corporais veiculadas pelos meios de comunicação, entre eles as revistas masculinas, nos chamam a atenção para a percepção da centralidade que possui a aparência física nas interações sociais da cultura brasileira como um todo. 


\title{
Referências
}

ADORNO, T. \& HORKHEIMER, M. Dialética do esclarecimento. Rio de Janeiro: Jorge Zahar, 1985.

BARTHES, R. A mensagem fotográfica. In: LIMA, Luiz Costa. Teoria da cultura de massa. 7. ed. - São Paulo: Paz e terra, 2005.

BENJAMIN, W. A obra de arte na época de sua reprodutibilidade técnica. In: LIMA, Luiz Costa. Teoria da cultura de massa. 7. ed. São Paulo: Paz e terra, 2005.

BETTI, M. A janela de vidro: esporte, televisão e educação Física. Campinas: Papirus, 1998.

ELIAS, N. O processo civilizador. Rio de janeiro: Jorge Zahar, 1994. V. 1.

GOLDENBERG, Mirian; RAMOS, Marcelo Silva. A civilização das formas. In: GOLDENBERG, M. Nu e vestido: dez antropólogos revelam a cultura do corpo carioca. Rio de Janeiro: Record, 2002.

HOR KHEIMER, M. Eclipse da razão. São Paulo: Centauro, 2000.

LIMA, L. C. Teoria da cultura de massa. 7. ed. São Paulo: Paz e Terra, 2005.

PIRES, G. DE L. Educação Física e o discurso midiático. Ijuí: Ed. Unijuí, 2002.

SILVA, P. N. G.; GOMES, E. S. L. Eternamente jovem: corpo malhado, ficção televisual e imaginário. Revista Pensar a Prática, Goiânia, v. 11, n. 2, p. 197-207, ago. 2008.

VAZ, A. F. Reflexões de passagem sobre o lazer: notas sobre a pedagogia da indústria cultural. Revista Pensar a Prática, v. 9, n. 1, p. 13-26, jun. 2006.

\section{Commodification of the female body: a study on the fotographic image of naked woman}

\begin{abstract}
This paper reports a survey conducted during 2009 based on the fundamentals of phenomenology. The object of study was naked female body displayed as an art form in "Playboy" magazine published in 2008. The method used was Photographic Analysis of Roland Barthes (2005), which seems photography as a phenomenon capable of being analyzed and that composes the picture of the so-called Cultural Industry. This article deals specially with the female body in contemporary society, its standardized aesthetic constitution and the mechanisms of depreciation to which it is submitted.
\end{abstract}

Keywords: photograph; body; woman; commodity; cultural industry.

\section{La mercantilización del cuerpo femenino: un studio sobre la imagen fotográfica de la mujer desnuda}

\begin{abstract}
Resumen
Este documento es un informe de una encuesta realizada en 2009, bajo los cimientos de la fenomenología, en la que el objeto de estudio fue el cuerpo femenino desnudo que aparece como una forma de arte en publicaciones nombradas como Playboy, publicadas en 2008. El método utilizado consistió en un análisis fotográfico de Roland Barthes (2005), que trata la fotografía como un fenómeno que puede leerse y que hace parte de la designada industria cultural. El artículo trata efectivamente del cuerpo de la mujer en la sociedad contemporánea, la constitución de una norma estética y los mecanismos de la depresión que está sujeta.
\end{abstract}

Palabras Clave: fotografía; cuerpo; mujer; mercancía; la industria cultural. 